Research

Open Access

\title{
Interference by new-generation mobile phones on critical care medical equipment
}

\author{
Erik Jan van Lieshout ${ }^{1,2}$, Sabine N van der Veer ${ }^{3}$, Reinout Hensbroek ${ }^{4}$, Johanna C Korevaar ${ }^{5}$, \\ Margreeth B Vroom ${ }^{1}$ and Marcus J Schultz ${ }^{1,6}$
}

\begin{abstract}
1Department of Intensive Care Medicine, Academic Medical Centre, University of Amsterdam, Meibergdreef 9, 1105 AZ Amsterdam, The Netherlands 2Mobile Intensive Care Unit, Academic Medical Centre, University of Amsterdam, Meibergdreef 9, 1105 AZ Amsterdam, The Netherlands ${ }^{3}$ Department of Medical Engineering, Academic Medical Centre, University of Amsterdam, Meibergdreef 9, 1105 AZ Amsterdam, The Netherlands ${ }^{4}$ Department of Prevention and Health, Netherlands Organisation for Applied Scientific Research, Zernikedreef 9, 2333 CK Leiden, The Netherlands ${ }^{5}$ Department of Clinical Epidemiology, Biostatistics and Bioinformatics, Academic Medical Centre, University of Amsterdam, Meibergdreef 9, 1105 AZ Amsterdam, The Netherlands

6Laboratory of Experimental Intensive Care and Anaesthesiology, Academic Medical Centre, University of Amsterdam, Meibergdreef 9, 1105 AZ Amsterdam, The Netherlands
\end{abstract}

Corresponding author: Erik Jan van Lieshout, e.j.vanlieshout@amc.nl

Received: 18 Apr 2007 Revisions requested: 24 May 2007 Revisions received: 12 Jun 2007 Accepted: 6 Sep 2007 Published: 6 Sep 2007

Critical Care 2007, 11:R98 (doi:10.1186/cc6115)

This article is online at: http://ccforum.com/content/11/5/R98

(c) 2007 van Lieshout et al.; licensee BioMed Central Ltd.

This is an open access article distributed under the terms of the Creative Commons Attribution License (http://creativecommons.org/licenses/by/2.0), which permits unrestricted use, distribution, and reproduction in any medium, provided the original work is properly cited.

\begin{abstract}
Introduction The aim of the study was to assess and classify incidents of electromagnetic interference (EMI) by secondgeneration and third-generation mobile phones on critical care medical equipment.

Methods EMI was assessed with two General Packet Radio Service (GPRS) signals $(900 \mathrm{MHz}, 2 \mathrm{~W}$, two different time-slot occupations) and one Universal Mobile Telecommunications System (UMTS) signal (1,947.2 MHz, 0.2 W), corresponding to maximal transmit performance of mobile phones in daily practice, generated under controlled conditions in the proximity of 61 medical devices. Incidents of EMI were classified in accordance with an adjusted critical care event scale.
\end{abstract}

Results A total of 61 medical devices in 17 categories $(27$ different manufacturers) were tested and demonstrated 48 incidents in 26 devices (43\%); 16 (33\%) were classified as hazardous, $20(42 \%)$ as significant and $12(25 \%)$ as light. The GPRS-1 signal induced the most EMI incidents $(41 \%)$, the GRPS-2 signal induced fewer $(25 \%)$ and the UMTS signal induced the least $(13 \% ; P<0.001)$. The median distance between antenna and medical device for EMI incidents was 3 $\mathrm{cm}$ (range 0.1 to $500 \mathrm{~cm}$ ). One hazardous incident occurred beyond $100 \mathrm{~cm}$ (in a ventilator with GRPS-1 signal at $300 \mathrm{~cm}$ ).

Conclusion Critical care equipment is vulnerable to EMI by new-generation wireless telecommunication technologies with median distances of about $3 \mathrm{~cm}$. The policy to keep mobile phones ' 1 meter' from the critical care bedside in combination with easily accessed areas of unrestricted use still seems warranted.

\section{Introduction}

Electromagnetic interference (EMI) with medical equipment by second-generation mobile phones has been reported extensively and seems clinically relevant to about $10 \%$ of medical devices [1-7]. The growth in use and the decrease in size of mobile phones intensifies the discussion on present hospital restrictions on the use of mobile phones in patient areas, which is violated by healthcare workers themselves to improve patient care by better communication [8]. Critical incidents caused by mobile phones are probably rare but are potentially lethal and are most probably not recognized as such $[9,10]$.

First-generation mobile phones are mainly used for voice, whereas new generations of telecommunication systems enable us to have wireless internet access to send and receive data even at the patient's bedside [11]. Data transmission may be of more concern in the context of EMI. However, these new systems entered the market with limited proof of their safety in 
the critical care environment [12]. Unfortunately, studies on EMl-induced incidents are characterized by a technical description of incidents only, whereas classification of their clinical relevance is needed to update evidence-based policies on the use of modern mobile phones $[3,13]$.

The aim of the present study was to assess and classify incidents of EMI by second-generation and third-generation telecommunication signals on 61 critical care devices.

\section{Methods \\ Medical equipment}

In all, 61 different medical devices (27 different manufacturers) in 17 categories were allocated for EMI tests (Table 1). The details of the devices are summarized in Additional file 1. All devices were tested in accordance with an international test protocol during full operation and in different modes; a simulator (namely an electrocardiogram simulator, an artificial lung and a syringe filled with saline) was connected if relevant [14]. The tests were performed on devices in use for patient care by two different hospitals (Academic Medical Center, Amsterdam, The Netherlands, and Kennemer Gasthuis, Haarlem, The Netherlands) to maximize the number of devices; similar test conditions were used in each location.

\section{Signals}

The General Packet Radio Service (GPRS) signals had timeslot durations of $1,113 \mu$ s and a repetition frequency of 217 $\mathrm{Hz}$ (GRPS-1) or $556.5 \mu$ at $27.1 \mathrm{~Hz}$ (GPRS-2), both with a $0.2 \mathrm{MHz}$ channel bandwidth and a carrier frequency of 900 $\mathrm{MHz}$. This GPRS technology, based on time-division multipleaccess technology and available for data transfer in Europe, the United States, Australia and parts of Asia, was chosen for its forthcoming use for data transmission [11]. GPRS is considered a 2.5-generation wireless telephony system.

The Universal Mobile Telecommunications System (UMTS) signal had a bandwidth of $5 \mathrm{MHz}$ and a carrier frequency of 1,947.2 $\mathrm{MHz}$. This wideband code-division multiple-access frequency-division duplex technology is considered a thirdgeneration wireless telephony system. A signal generator (HP/ Agilent E4433B/ESG-D Digital RF $250 \mathrm{kHz}$ to $4 \mathrm{GHz}$ ), provided with a Global System for Mobile Communications (GSM)/W-CDMA module, was used in combination with external control equipment (a laptop and an additional pulse generator) for timing purposes. The signals were amplified and their power level was controlled at $2 \mathrm{~W}$ for GRPS in active time slots and at $0.2 \mathrm{~W}$ for UMTS. These power levels correspond to maximal transmit performance of mobile phones in daily practice and were chosen to mimic a worst-case but realistic scenario to maximize the chance of detecting EMI-related incidents.

The signals were radiated towards the medical apparatus through an electrically balanced handheld antenna without reflecting obstacles nearby. Special attention was paid to poorly shielded locations in device housings (such as connectors, sensors, and seams in the housing). The initial distance between antenna and device was $500 \mathrm{~cm}$ from the device housing and was decreased to $0 \mathrm{~cm}$ or until any incident occurred [14]. In the event of any interference the test was repeated three times to assess reproducibility.

\section{Classification of incidents}

Incidents observed during the normal operation of each device were documented in detail. Two board-certified and experienced intensivists classified by consensus of opinions the severity of the observed incidents in accordance with an adjusted scale of critical care adverse events [15]. The scale ranges from light (influence on monitoring without a significant level of attention needed, for example a disturbed display) through significant (influence on monitoring with a significant level of attention needed, causing substantial distraction from patient care, for example an incorrect alarm or inaccurate monitoring of blood pressure) to hazardous (direct physical influence on the patient by an unintended change in equipment function, for example total stopping of ventilator or syringe pump).

\section{Statistical analysis}

Median, maximum and minimum are given if no normal distribution was established. Distances are expressed in centimetres. The distance between the antenna and device was set at 0.1 $\mathrm{cm}$ if an incident occurred when the antenna was held against the housing of the device. Percentages of critical care devices disturbed by second-generation and third-generation telecommunication signals (GPRS-1, GPRS-2 and UMTS) were compared by using Cochran's $Q$ test. The difference between median distances between antenna and device at which incidents occurred were analysed with the Friedman test. A linearby-linear $\chi^{2}$ test was performed to test for a trend in the frequency of incidents in relation to the year of purchase of the device.

\section{Results}

EMI by GPRS or UMTS signals on critical care medical equipment was demonstrated in 26 of the 61 device tests (43\%) (Table 1). A total of 48 incidents were identified and classified as $16(33 \%)$ hazardous, $20(42 \%)$ significant and $12(25 \%)$ light.

The GPRS-1 signal induced the highest number of incidents of EMI: $41 \%$ (25 of 61 ), followed by GRPS-2 (25\%; 15 of 61 ) and UMTS $(13 \% ; 8$ of $61 ; P<0.001)$. The same was true of the hazardous incidents: GPRS-1 20\% (12 of 61), GPRS-2 $5 \%$ (3 of 61 ) and UMTS $2 \%$ ( 1 of $61 ; P<0.001)$. The medical devices and descriptions of all incidents are listed in Additional file 1 . 
Table 1

Categories of medical devices, interference distances and type of incidents per signal

\begin{tabular}{|c|c|c|c|c|c|c|}
\hline \multirow[t]{2}{*}{ Type of device or incident } & \multicolumn{2}{|c|}{ Number of devices } & \multirow[t]{2}{*}{ Distance $^{a}(\mathrm{~cm})$} & \multicolumn{3}{|c|}{ Type of incident per signal ${ }^{b}$} \\
\hline & Tested & Influenced & & GPRS-1 & GPRS-2 & UMTS \\
\hline Intensive care unit ventilator & 9 & 7 & $1.5[0.1-300]$ & $6 \mathrm{H}, 1 \mathrm{~L}$ & $2 \mathrm{H}, 1 \mathrm{~S}, 1 \mathrm{~L}$ & $1 \mathrm{H}, 2 \mathrm{~S}, 1 \mathrm{~L}$ \\
\hline Critical care monitor & 13 & 7 & $3[0.1-500]$ & $4 \mathrm{~S}, 3 \mathrm{~L}$ & $2 \mathrm{~S}, 4 \mathrm{~L}$ & \\
\hline Syringe pump & 7 & 3 & $5[0.1-50]$ & $2 \mathrm{H}, 1 \mathrm{~S}$ & $\mathrm{~S}$ & $\mathrm{~S}$ \\
\hline Volumetric infusion pump & 4 & 1 & 30 & $S$ & $S$ & $S$ \\
\hline Intra-aortic balloon pump & 2 & 1 & 0.1 & L & & \\
\hline Haemofiltration/dialysis & 5 & 1 & 15 & $\mathrm{H}$ & & \\
\hline External pacemaker & 4 & 1 & 3 & $\mathrm{H}$ & & \\
\hline Defibrillator & 3 & 1 & 0.1 & & & L \\
\hline 12-lead EKG & 1 & 1 & 150 & $\mathrm{~S}$ & $\mathrm{~S}$ & $S$ \\
\hline Fluid warmer & 2 & 1 & 6 & $S$ & $S$ & \\
\hline Enteral feeding pump & 2 & 1 & 30 & $\mathrm{H}$ & $\mathrm{H}$ & \\
\hline Air humidifier & 1 & 1 & 5 & $\mathrm{H}$ & & \\
\hline EKG telemetry & 1 & 0 & & & & \\
\hline Forced-air warming unit & 3 & 0 & & & & \\
\hline Mobile suction unit & 1 & 0 & & & & \\
\hline Critical care bed & 2 & 0 & & & & \\
\hline Continuous-airflow mattress & 1 & 0 & & & & \\
\hline \multicolumn{7}{|l|}{ Type of incident ${ }^{b}$} \\
\hline Hazardous & & & $3.5[0.1-300]$ & & & \\
\hline Significant & & & $25[0.1-500]$ & & & \\
\hline Light & & & $0.1[0.1-3]$ & & & \\
\hline Total & 61 & $26(43 \%)$ & $3[0.1-500]$ & $25(41 \%)$ & $15(25 \%)$ & $8(13 \%)$ \\
\hline
\end{tabular}

GPRS, General Packet Radio Service; UMTS, Universal Mobile Telecommunications System; EKG, electrocardiogram. aResults are shown as median [range]. bHazardous $(\mathrm{H})$ is defined as a direct physical influence on patient by unintended change in equipment function; significant (S) is defined as an influence on monitoring with a significant level of attention needed, causing substantial distraction from patient care; light ( $\mathrm{L}$ ) is defined as an influence on monitoring without a significant level of attention needed.

Hazardous incidents occurred in devices for therapy only due to the definitions of the adjusted critical adverse events scale. In mechanical ventilators, nine hazardous incidents (in seven ventilators out of nine tested; median distance $3 \mathrm{~cm}$, range 0.1 to 300 ) varied from 'total switch-off and restart' to changes in set ventilation rate. In syringe pumps, two hazardous incidents (in two pumps out of seven tested; distances 0.1 and $2 \mathrm{~cm}$ ) demonstrated a complete stop without an acoustic alarm or with an incorrect alarm. One hazardous incident in a renal replacement device (out of five machines tested; distance 15 $\mathrm{cm}$ ) showed a stop after an incorrect air detector alarm. One external pacemaker (out of three tested; distance $3 \mathrm{~cm}$ ) demonstrated a hazardous incident, with incorrect inhibition of the pacemaker.
The median distance between antenna and device at which all type of incident occurred was $3 \mathrm{~cm}$, range $(0.1$ to $500 \mathrm{~cm})$. The relation between distance and number of hazardous, light and significant incidents is depicted in Figure 1.

Incidents occurred at greater distance with the GPRS-1 signal (median $5 \mathrm{~cm}$ ) than with the GPRS-2 (median $3 \mathrm{~cm}$ ) or UMTS (median $1 \mathrm{~cm}$ ) signal, although the differences were not statistically significant $(P=0.12)$.

Hazardous incidents occurred at a median distance of $3.5 \mathrm{~cm}$ (range 0.1 to $300 \mathrm{~cm}$ ). Beyond $100 \mathrm{~cm}$ one hazardous incident at $300 \mathrm{~cm}$ in a ventilator with the GRPS-1 signal and two significant incidents occurred at $150 \mathrm{~cm}$ in a 12-lead electrocardiogram device with GPRS 1, GPRS-2 and UMTS signals (see Additional file 1). 
Figure 1

\section{relation between \\ distance and number of incidents}

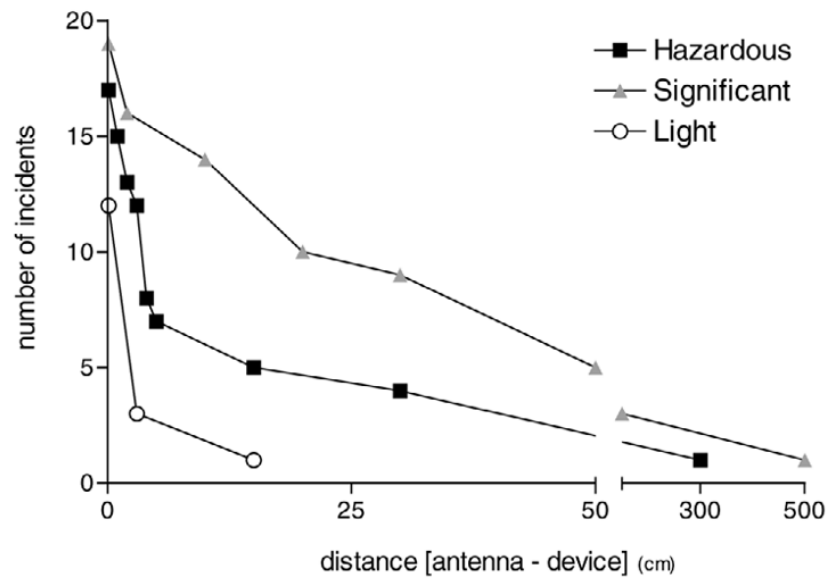

Relation between distance and number of incidents.

No relation could be demonstrated between the year of purchase of medical devices and the number of incidents $(P=$ 0.67).

\section{Discussion}

The present study demonstrates two new findings in the field of interference by mobile phones on medical equipment.

First, the 2.5-generation mobile communication network GPRS is able to induce a higher rate of EMI incidents than is known for the first-generation network GSM at comparable distances $[1,3,7]$. Second, the median distance at which EMI incidents caused by new-generation cellular phones take place $(3 \mathrm{~cm})$ falls within the '1 meter rule' proposed as a safe distance in patient areas, although the range demonstrated in this study is considerable $(0.1$ to $500 \mathrm{~cm})[1,5,11,16]$.

Studies on EMI by first-generation mobile phones have been based on the GSM network used in Europe, the United States, Australia and part of Asia, or on code-division multiple access (CDMA), which is used mostly in the United States [2,3]. Meanwhile GPRS and UMTS networks are used for their advanced properties to transmit video and data wirelessly at a higher speed as well as regular voice telephony [12].

Our finding of EMI induced by UMTS with hazardous incidents contrasts with what was demonstrated recently in the only study so far on UMTS by Wallin and colleagues [12]. No critical UMTS incidents with 76 medical devices were reported besides interference noise on loudspeakers of two ultrasonic Doppler devices. Their only critical incident with GPRS was the total stopping of one infusion pump (out of 12 tested) at a distance of $50 \mathrm{~cm}$. Neither GPRS nor UMTS demonstrated any interference on four intensive care ventilators tested.
Three of those ventilators were also tested in our study, and in contrast with those studied by Wallin and colleagues they showed significant and hazardous GRPS incidents and one light UMTS incident. There are two possible explanations for these differences. First, Wallin and colleagues used a different GPRS signal with a frequency of $1,800 \mathrm{MHz}$ and an output power of $1 \mathrm{~W}$, as opposed to $900 \mathrm{MHz}$ and $2 \mathrm{~W}$ used in the present study. The lower carrier-wave frequency of the GPRS signal and the corresponding $2 \mathrm{~W}$ in our study was chosen for its availability in many continents. GPRS is used worldwide on different frequency bands (900 and $1,800 \mathrm{MHz}$ ) in different continents and therefore many 'tri-band or quad-band' mobile phones are sold for their worldwide operation $[3,13]$. Second, the studies differed in their selection from medical equipment available worldwide. Our results apply to the tested devices only as specified, including the year of purchase, and consequently are a limitation of the present study.

Another limitation of this study is the test conditions. The only method for obtaining reproducible results in testing EMI by mobile phones is a standard signal generator to control output power as used in the study by Wallin and colleagues and in our own $[3,12]$. The use of commercially available mobile phones in ringing mode will generate irreproducible results at different locations because mobile phones (GSM, GPRS and UMTS) regulate their output power depending on the nearest cell base station for the telecom provider $[4,17]$. If such a station is nearby, a mobile phone constantly minimizes its required output power, in GPRS to as low as 5 to $10 \%$ (50 to $100 \mathrm{~mW}$ ), to increase its battery lifespan. In our study the output power was controlled and set at the maximum level to mimic a worst-case but realistic scenario. In healthcare facilities the coverage of telecommunication networks could be poor because of its structures and could consequently induce mobile phones to transmit at maximum power, which increases the risk of EMI $[1,12]$. Therefore, as a result of our worst-case scenario it is not to be expected that in daily practice critical EMI incidents with GPRS or UMTS would be more frequent than reported in our study.

Health care applications of new wireless telecommunication technologies are reaching the bedside (namely intelligent pager systems with smart phones, personal digital assistants with internet access, and telemonitoring interhospital intensive care transport) with potential clinical benefits $[2,8]$. However, critical care equipment, with closed loop systems to eliminate human resources and errors, demands permanent technology assessment to ensure its continued performance including electromagnetic compatibility with other devices [2].

The international standard on electromagnetic compatibility by the International Electrotechnical Commission in its present form is insufficient to safeguard medical equipment completely from EMI by GSM mobile phones, and our results show that the same holds true for GPRS and UMTS signals $[11,18]$. The 
present industrial standard lacks stipulations for eliminating EMI in medical equipment. Manufacturers are allowed to comply with the standard by reporting only the distance at which EMI occurs. Reasons why even new medical devices still demonstrate EMI caused by mobile phones would be speculative; examples are complex medical industrial design, rapidly changing telecommunications signals, and costs. This leads one to suspect that the undesirable situation of EMI in the critical care environment will not be eradicated soon.

This study adds to the objective evidence that restrictive use in the critical care environment is sensible without overstressing negligible risks $[11,19]$.

\section{Conclusion}

The '1 meter rule', specifying the minimum distance to keep a mobile phone from medical equipment or the bedside as proposed in the past, seems safe, although the rule does not exclude EMI by new-generation mobile phones entirely. Restrictive policies should be facilitated by offering numerous areas that are easily accessed throughout the healthcare facility where the use of mobile phones is clearly permitted.

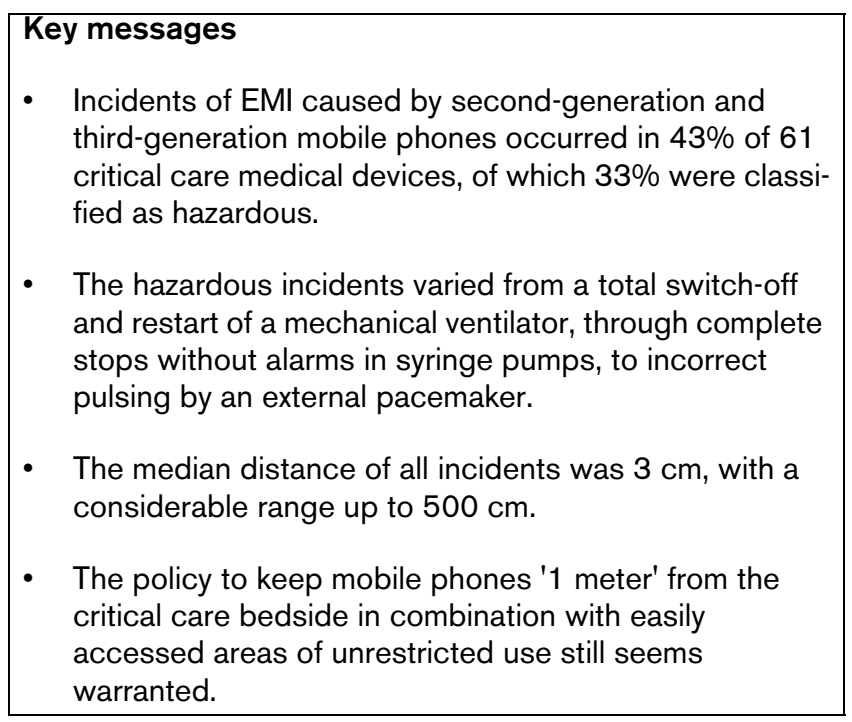

\section{Competing interests}

The authors declare that they have no competing interests.

\section{Authors' contributions}

EJvL designed the study, performed the measurements, assisted in the statistical analyses and drafted the manuscript. SNvdV designed the study, helped in performing the measurements and interpreting the results and participated in drafting the manuscript. $\mathrm{RH}$ designed the study, performed the measurements and participated in drafting the manuscript. JCK performed the statistical analysis and participated in drafting the manuscript. MBV and MJS participated in the study design, in interpreting the results and in drafting the manuscript. All authors read and approved the final manuscript.

\section{Additional files}

The following Additional files are available online:

\section{Additional file 1}

An Excel file containing a list of medical devices and descriptions of all incidents.

See http://www.biomedcentral.com/content/ supplementary/cc6115-S1.xls

\section{Acknowledgements}

The authors thank the Department of Medical Engineering, Academic Medical Center, Amsterdam, the Kennemer Gasthuis Haarlem, Dave Dongelmans MD, and Royal KPN N.V., The Hague, for their logistical and technical assistance and expertise. $\mathrm{RH}$ received an unrestricted research grant ('MICU Connected') from Royal KPN N.V. for the present study.

\section{References}

1. Mobile Communications Interference [http:www.mhra.gov.uk/ home/idcplg?ldcServ ice=SS GET PAGE\&nodeld=261]

2. International Organization for Standardization (ISO): Health Informatics - Use of Mobile Wireless Communication and Computing Technology in Healthcare Facilities Geneva: ISO; 2005. [Report no. ISO/TR 21730:2005.]

3. Lawrentschuk N, Bolton DM: Mobile phone interference with medical equipment and its clinical relevance: a systematic review. Med J Aust 2004, 181:145-149.

4. Tri JL, Severson RP, Hyberger LK, Hayes DL: Use of cellular telephones in the hospital environment. Mayo Clin Proc 2007, 82:282-285.

5. Shaw Cl, Kacmarek RM, Hampton RL, Riggi V, El Masry A, Cooper JB, Hurford WE: Cellular phone interference with the operation of mechanical ventilators. Crit Care Med 2004, 32:928-931.

6. Barbaro V, Bartolini P, Benassi M, Di Nallo AM, Reali L, Valsecchi $S$ : Electromagnetic interference by GSM cellular phones and UHF radios with intensive-care and operating-room ventilators. Biomed Instrum Technol 2000, 34:361-369.

7. Irnich WE, Tobisch R: Mobile phones in hospitals. Biomed Instrum Technol 1999, 33:28-34.

8. Soto RG, Chu LF, Goldman JM, Rampil IJ, Ruskin KJ: Communication in critical care environments: mobile telephones improve patient care. Anesth Analg 2006, 102:535-541.

9. Hahn IH, Schnadower D, Dakin RJ, Nelson LS: Cellular phone interference as a cause of acute epinephrine poisoning. Ann Emerg Med 2005, 46:298-299.

10. Anonymous: Wireless communication devices and electromagnetic interference. ECRI's updated recommendations. Health Devices 2001, 30:403-409.

11. Lapinsky SE, Easty AC: Electromagnetic interference in critical care. J Crit Care 2006, 21:267-270.

12. Wallin MK, Marve T, Hakansson PK: Modern wireless telecommunication technologies and their electromagnetic compatibility with life-supporting equipment. Anesth Analg 2005, 101:1393-1400.

13. Ettelt S, Nolte E, McKee M, Haugen OA, Karlberg I, Klazinga $N$, Ricciardi W, Teperi J: Evidence-based policy? The use of mobile phones in hospital. J Public Health (Oxf) 2006, 28:299-303.

14. Institute of Electrical and Electronics Engineers: American National Standard Recommended Practice for On-site ad hoc Test Method for Estimating Radiated Electromagnetic Immunity of Medical Devices to Specific Radio-frequency Transmitters (Standard C63.18) Piscataway, NJ: IEEE; 1997.

15. Kivlahan C, Sangster W, Nelson K, Buddenbaum J, Lobenstein K: Developing a comprehensive electronic adverse event report- 
ing system in an academic health center. Jt Comm J Qual Improv 2002, 28:583-594.

16. Imhoff M: Everybody on the phone? Anesth Analg 2006, 102:533-534.

17. Lönn $S$, Forssén U, Vecchia $P$, Ahlbom A, Feychting M: Output power levels from mobile phones in different geographical areas; implications for exposure assessment. Occup Environ Med 2004, 61:769-772.

18. IEC: Medical Electrical Equipment. Part 1-2: General Requirements for Safety - Collateral Standard: Electromagnetic Compatibility - Requirements and Tests Geneva: International Electrotechnical Commission; 2004. [Report no. IEC 60601-12:2001+A1:2004.]

19. Derbyshire SW, Burgess A: Use of mobile phones in hospitals. $B M J$ 2006, 333:767-768. 